\title{
Nguyên lý tài chính-toán của thị trường chứng khoán
}

Vương Quân Hoàng \& Ngô Phương Chí

10 December 2000

(Ngày xuất bản)

Nhà xuất bản Chính trị Quốc gia, Hà Nội

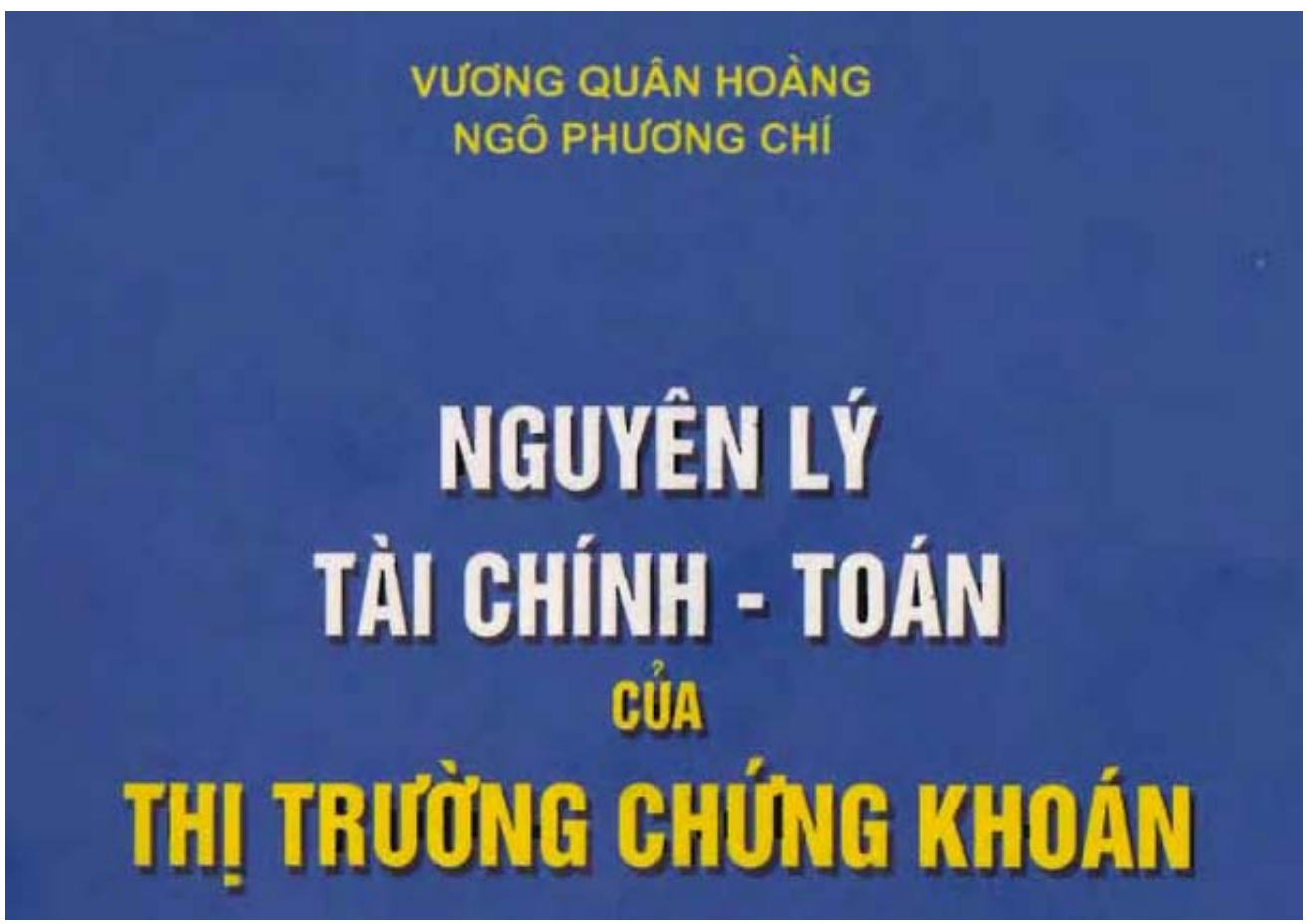

Thông tin lấy theo bản ghi Record 4098 từ hệ thống tra cứu Internet tập trung của

Thư Viện Quốc Hội Việt Nam

The National Assembly Library of Vietnam 


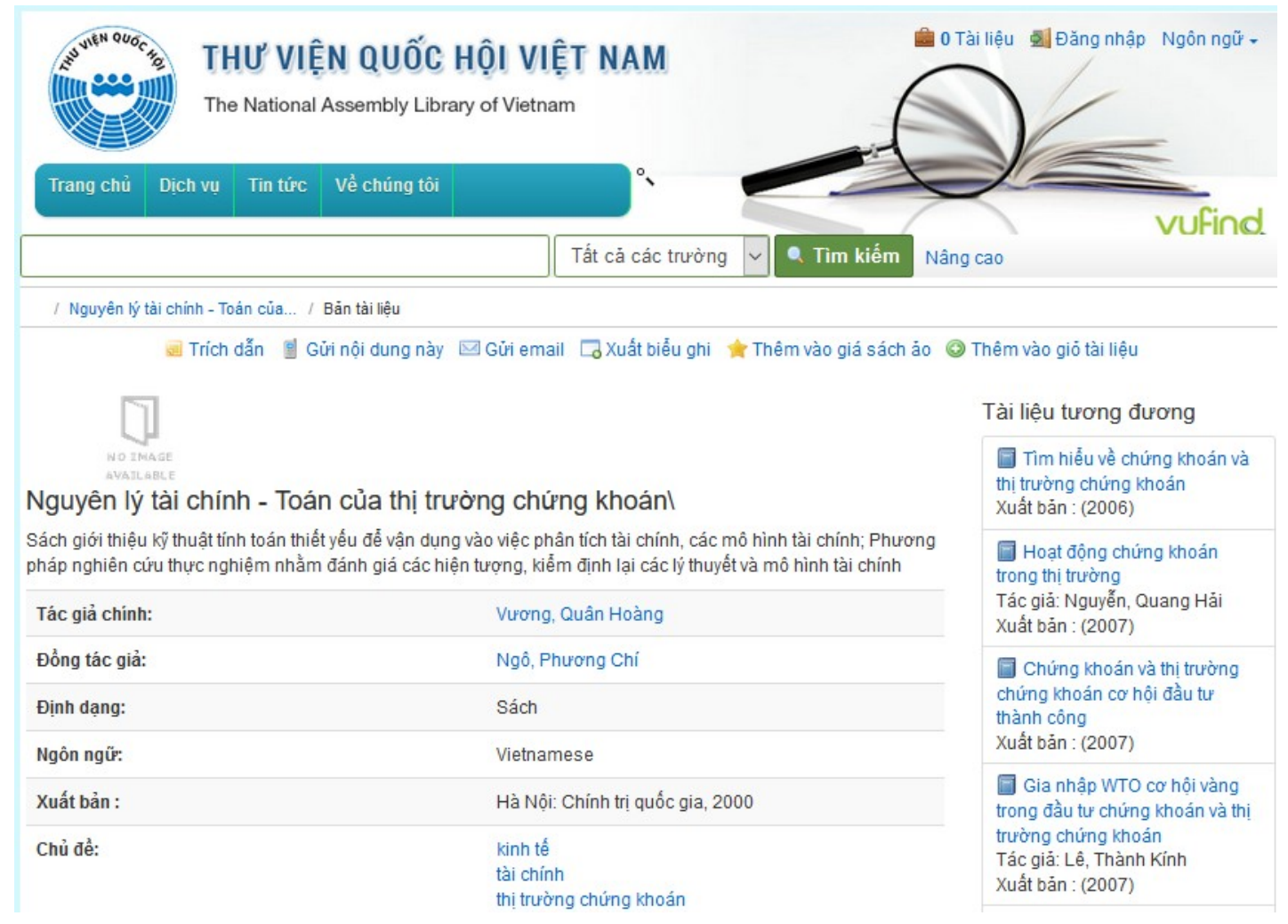

https://tracuutaptrung.quochoi.vn/Record/4098 (truy cập ngày: 20/02/2021)

Văn bản điện tử cũng được lưu trữ trên Google Books, tại địa chỉ Internet: https://books.google.com/books?id=t-V6HpkdUTMC (truy cập ngày: 20/2/2021) 
Nguyên lý tài chính - Toán của thị trường chứng khoán\

Sách giới thiệu kỹ thuật tính toán thiết yếu để vận dụng vào việc phân tích tài chính, các mô hình tài chính; Phương pháp nghiên cứu thực nghiệm nhằm đánh giá các hiện tượng, kiểm định lại các lý thuyết và mô hình tài chính

Tác giả chính:

Đồng tác giả:

Định dạng:

Ngôn ngữ:

Xuất bản :

Chủ đề:

Thẻ:
Vương, Quân Hoàng

Ngô, Phương Chí

Sách

Vietnamese

Hà Nội: Chính trị quốc gia, 2000

kinh tế

tài chính

thị trường chứng khoán

Không có thẻ nào, Hãy là người đầu tiên đánh dấu biểu ghi này!

Bản tài liệu Miêu tả Bình luận Tài liệu tương đương Giao diện nhân viên

Thu vien Quoc Hoi:

Call Number:

Bản Unknown

Bản Unknown
$332.6 \mathrm{Ng} 527 \mathrm{I}$

Săn sàng Đặt mượn

Sãn sàng Đặt mượn 
Nguyên lý tài chính - Toán của thị trường chứng khoánl

Sách giới thiệu kỹ thuật tính toán thiết yếu để vận dụng vào việc phân tích tài chính, các mô hình tài chính; Phương pháp nghiên cứu thực nghiệm nhằm đánh giá các hiện tượng, kiểm định lại các lý thuyết và mô hình tài chính

Tác giả chính:

Đồng tác giả:

Định dạng:

Ngôn ngữ:

Xuất bản :

Chủ đề:

Thẻ:
Vương, Quân Hoàng

Ngô, Phương Chí

Sách

Vietnamese

Hà Nội: Chính trị quốc gia, 2000

kinh tế

tài chính

thị trường chứng khoán

Không có thẻ nào, Hãy là người đầu tiên đánh dấu biểu ghi này!

\section{+ Thêm từ khóa}

Bản tài liệu Miêu tả Bình luận Tài liệu tương đương Giao diện nhân viên

LEADER $\quad 01357$ nam a2200277 a 4500

$001 \quad 4235$

$005 \quad 20161019034155.0$

008 041007s2000\#\#\#\#v |||||||||||||||||vie||

$040 \quad$ a TVQH |b vie |e AACR2

$041 \quad$ a vie

$080 \quad$ |a 31

082

|2 23 |a 332.6 |b Ng527|

100

|a Vương, Quân Hoàng

2451 |a Nguyên lý tài chính - Toán của thị trường chứng khoán\ |c Vương Quân Hoàng, Ngô Phương Chí

|a Hà Nội: |b Chính trị quốc gia, |c 2000 
300

|a 304tr.

520

|a Sách giới thiệu kỹ thuật tính toán thiết yếu để vận dụng vào việc phân tích tài chính, các mô hình tài chính; Phương pháp nghiên cứu thực nghiệm nhằm đánh giá các hiện tượng, kiểm định lại các lý thuyết và mô hình tài chính

653

|a kinh tế

653

|a tài chính

653

|a thị trường chứng khoán

700

|a Ngô, Phương Chí

911

|a Convert |b 07/10/2004 |c Administrator |d NAL040004294

942

lc BK

999

|c 4098 |d 4098

952

|0 0 |1 0 | |2 ddc |4 0 |6 332_600000000000000_NG527L |7 0 |9 9932

|a TVQH |b TVQH |c P1-HV |d 2004-10-07 |e Khác |o 332.6 Ng527|

|p VV00012069 |r 2015-12-29 |w 2015-12-29 |y BK

952

|0 0 |1 0 | |2 ddc |4 0 |6 332_600000000000000_NG527L |7 0 |9 9933

|a TVQH |b TVQH |c P1-HV |d 2004-10-07 |e Khác |o 332.6 Ng527|

|p VV00012070 |r 2015-12-29 |w 2015-12-29 |y BK 